\title{
Marketing Digital como Estratégia Competitiva dentro das Organizações: Um Estudo de Caso em uma Rede Empresarial na Região do Cariri - CE
}

Francisco Wagner Alves da Silva ${ }^{1}$; Pedro Ferreira de Lima ${ }^{2}$; Márcia Maria Leite Lima ${ }^{3}$

Resumo: A comunicação via mídias e redes sociais digitais é uma atividade estratégica de suporte para alavancar as vendas de produtos e serviços de empresas. O objetivo geral deste estudo é avaliar a influência do marketing digital sob o volume de vendas em um grupo empresarial da Região do Cariri - CE. Para o alcance dos resultados foi realizado um estudo bibliográfico, analise documental, com métodos estatísticos inferencial, descritiva, de cunho quantitativa, através de teste de normalidade. Os resultados deste estudo evidenciam que é fundamental o gerenciamento das mídias digitais dentro de uma organização. Foi observado que a implantação das mídias digitais dentro do grupo empresarial de um modo geral não afetou de forma positiva as vendas.

Palavras Chave: Marketing. Planejamento Estratégico. Marketing Digital.

\section{Digital Marketing as a Competitive Strategy within Organizations: A Case Study in a Business Network in the Region of Cariri, State of Ceará}

\begin{abstract}
Communication via digital media and social networks is a strategic support activity to leverage sales of corporate products and services. The general objective of this study is to evaluate the influence of digital marketing under sales volume in a business group in the Region of Cariri - CE. In order to reach the results, a bibliographic study, documentary analysis, was carried out using statistical methods, inferential, descriptive, quantitative, through a normality test. The results of this study show that the management of digital media within an organization is fundamental. It was noted that the deployment of digital media within the business group generally did not affect sales positively.
\end{abstract}

Keywords: Marketing. Strategic planning. Digital marketing.

\section{Introdução}

A era digital é uma constante no dia a dia das pessoas, as organizações procuram acompanhar esta nova realidade. Todos os números e estatísticas relacionados ao mundo digital

\footnotetext{
${ }^{1}$ Graduando o curso de Administração do Centro Universitário Doutor Leão Sampaio/Unileão - surto.com.br@ gmail.com;

${ }^{2}$ Centro Universitário Doutor Leão Sampaio/Unileão, Juazeiro do Norte, Ceará, Brasil.;

${ }^{3}$ Professora de graduação do Centro Universitário Doutor Leão Sampaio/Unileão especialista em Gestão de Estratégia e Pessoas-marcialeite@ leaosampaio.edu.br
} 
mudam a cada momento, mas o fundamental é entender o que esses estudos comprovam: trata-se de um caminho sem volta, que requer um aprendizado contínuo e apresenta grandes desafios e obstáculos a serem vencidos, mas que em contrapartida oferece uma gama inesgotável de possibilidades e oportunidades que, devidamente aproveitadas, podem render excelentes resultados.

Dentro do mundo digital estão as mídias sociais que ganham diariamente poder gigantesco nas sociedades, tornando um grande desafio para as empresas se inserir no meio para ganhar seguidores e assim atingir um fluxo maior de vendas. No Brasil, o crescimento da Internet tem sido impressionante, passando de 2,5 milhões de usuários em 1999 para mais de 139 milhões em 2017. Na tabela 01 apresenta o crescimento do número de internet nos últimos anos no Brasil.

Tabela 01: Crescimento do número de usuários de Internet no Brasil.

\begin{tabular}{|l|c|}
\hline Ano & Usuários da Internet \\
\hline 2016 & 139.111 .185 \\
\hline 2015 & 132.357 .306 \\
\hline 2014 & 118.700 .869 \\
\hline 2013 & 104.253 .986 \\
\hline 2011 & 98.286 .209 \\
\hline 2010 & 91.616 .484 \\
\hline 2009 & 80.736 .676 \\
\hline 2008 & 77.146 .249 \\
\hline 2007 & 65.890 .588 \\
\hline
\end{tabular}

Fonte: Extraído Turchi (2018).

De acordo a pesquisa "Jovem Digital Brasileiro" do Ibope, apresentada em 2014, feita com 1.513 jovens brasileiros com idade entre 15 e 32 anos, revelou que quase todos (96\%) usam a Internet diariamente para navegar nas redes sociais $(90 \%)$ e ver ou baixar vídeos. A distribuição entre as classes sociais é muito homogênea. Esses jovens possuem perfil em 7 redes sociais, em média, e em torno de 3 endereços de e-mail (17\% apenas um, $40 \%$ dois e $21 \%$ mais do que três). A maioria dos jovens entre 18 e 25 anos (91\%) usa constantemente o Facebook, 
$48 \%$ o YouTube, $15 \%$ o Instagram e $13 \%$ o Twitter. Entre os achados do estudo estão a simultaneidade e a convergência, uma vez que $61 \%$ deles estão habituados a usar mais de um meio de comunicação ao mesmo tempo e $63 \%$ assistem TV enquanto navegam na web, por isso os jovens também podem ser considerados multitelas. No total, mais de 90 milhões de usuários acessam a rede de suas casas ou trabalho, e o maior crescimento do acesso ocorreu nas residências: 87,9 milhões, o que representou um aumento de 19\% em um ano. Um quarto dos usuários ativos em residências no Brasil já utiliza banda larga com capacidade superior a 08 MB (TURCHI, 2018).

Como base nessa problemática surge a seguinte pergunta: As mídias sociais podem influenciar o crescimento de vendas de uma organização? Para resposta a esta problemática tem como hipóteses: as organizações empresariais que utilizam redes sociais possuem um maior poder de vendas. As redes sociais podem ser vista como uma ferramenta competitiva dentro da organização. A organização que não investe em redes sociais são menos competitivas. Para o alcance dessas respostas este estudo tem por objetivo geral avaliar a influência do marketing digital sob o volume de vendas em um grupo empresarial da Região do Cariri - CE. Seguido dos objetivos específicos: Estudar a influência das mídias online dentro das organizações; Colher informações sobre o volume de vendas antes da implantação nas lojas dos diversos segmentos; Colher informações sobre o volume de vendas após a implantação do marketing digital. Comparar o antes e o depois e avaliar a ocorrência do acréscimo das vendas, utilizandose de testes estatísticos e avaliar se o modo "impulsionar" nas publicações digitais traz efeito positivo no volume de vendas.

Esse trabalho se justifica pelo fato de que o mundo está cada vez mais conectado, noticias e informações chegam a tempo recorde. Com isso, a tecnologia em si torna-se primordial para as organizações aproveitarem o poder das redes sociais, elas não só devem, mas precisam entender como as pessoas se comunicam. Quanto à relevância deste estudo a pesquisa trará ao pesquisador novos conhecimentos e embasamento para tomadas de decisões gerenciais, no campo social e acadêmico. Os resultados serão vistos como fontes de pesquisas para melhorias continuas dentro de outras organizações. 


\section{Referencial Teórico}

\section{Planejamento Estratégico}

O surgimento do planejamento estratégico, na empresa privada, teve início na década de 50 (cinquenta) após à Segunda Guerra Mundial. Foi então que algumas empresas, americanas, principalmente, criaram sistemas de orçamentos anuais formalizados, com o objetivo de controlar melhor o fluxo das receitas e despesas. Assim, aos poucos, esses orçamentos anuais transformaram-se em projeções plurianuais, dando origem aos chamados planos quinquenais, que não passavam de projeções financeiras estáticas (GRACIOSO, 2007).

Já na visão de Oliveira (2018) o planejamento pode ser definido como o desenvolvimento de processos, técnicas e atitudes administrativas, as quais proporcionam uma situação viável de avaliar as implicações futuras de decisões presentes em função dos objetivos empresariais que facilitarão a tomada de decisão no futuro, de modo mais rápido, coerente, eficiente e eficaz.

Para uma melhor compreensão Oliveira (2018) apresenta no quadro 1 alguns aspectos do planejamento estratégico em relação as características básicas da função planejamento.

Quadro 01: Características básicas da função planejamento.

O planejamento não diz respeito a decisões futuras, mas às implicações futuras de decisões presentes (Drucker, 1962:131). Portanto, aparece como um processo sistemático e constante de tomada de decisões, cujos efeitos e consequências deverão ocorrer em futuros períodos de tempo.

O planejamento não é um ato isolado. Portanto, deve ser visualizado como um processo composto de ações inter-relacionadas e interdependentes que visam ao alcance de objetivos previamente estabelecidos. Deve-se, também, considerar a necessidade de os objetivos serem viáveis com base na validade das hipóteses em que se baseiam.

O processo de planejamento é muito mais importante que seu resultado final. O resultado final do processo de planejamento, normalmente, é o plano, sendo que esse deve ser desenvolvido "pela" empresa e não "para" a empresa. Se não for respeitado esse aspecto têm-se planos inadequados para a empresa, bem como níveis de resistência e de descrédito efetivos para sua implantação.

Fonte: Extraído Oliveira (2018). 
Como visto no quadro 1 acima percebe-se a necessidade de elaborar um planejamento para que direcione o caminho, mostrando vários cenários para uma melhor tomada de decisão, prevendo erros e viabilizando processos futuros, permitindo uma maior assertividade no alcance de metas previamente estabelecidos pela empresa (OLIVEIRA 2018).

O processo de planejar envolve, portanto, um modo de pensar; e um salutar modo de pensar envolve indagações; e indagações envolvem questionamentos sobre o que, como, quando, quanto, para quem, por que, por quem e onde fazer. Para isso, é importante antes de implantar uma estratégia dentro de sua organização é necessário distinguir primeiro o tipo de planejamento a ser feito. Na consideração dos grandes níveis hierárquicos, podem-se distinguir três tipos de planejamento:

Quadro 02: Tipos de planejamento.

\begin{tabular}{|c|}
\hline Planejamento estratégico \\
\hline Planejamento tático \\
\hline Planejamento operacional. \\
\hline Fonte: Extraído Oliveira (2018).
\end{tabular}

De forma global, os tipos de planejamento aos níveis de decisão são apresentados numa pirâmide organizacional, isso quer dizer que, o planejamento estratégico está relacionado ao nível estratégico da organização, que por sua vez, precisa de utilizar decisões estratégicas, com objetivos de longo prazo e com estratégias e ações para alcançá-los que afetam a empresa como um todo (OLIVEIRA 2018).

De acordo com Rocha (2015) um bom planejamento estratégico, poderá indicar a direção que a empresa deverá tomar, delimitando o caminho mais adequado para que ela possa responder às oportunidades do mercado e agregar valor aos consumidores.

Partindo desse pressuposto, Rocha (2015) afirma que existem vários conceitos para classificar o planejamento estratégico, e um deles refere-se à habilidade que uma empresa possui de identificar fatores no mercado, os quais possa incorporar a fim de conseguir ser melhor que os seus concorrentes e proporcionar mais satisfação aos seus consumidores. 


\section{Estratégias Empresariais como Ferramenta Competitiva}

A palavra estratégia existe há muito tempo, desde que mundo é mundo. Conforme poderá ser entendido, a estratégia está correlacionada à definição do conjunto de produtos e serviços versus segmentos de mercados proposto pela empresa em dado momento. A termologia estratégia significa, "a arte do general", tendo como origem a palavra grega strategos, que significa, estritamente, general. A estratégia, surgiu na Grécia Antiga, significava as tarefas de um general...Antes de Napoleão, estratégia significava a arte e a ciência de conduzir forças militares para derrotar o inimigo ou abrandar os resultados da derrota (OLIVEIRA, 2018).

Para Oliveira (2014) a estratégia não deve ser considerada como um plano fixo ou determinado, mas um esquema orientador dentro de um fluxo de decisões, ela deve ser sempre uma opção inteligente, econômica e viável. Portanto, é necessário reconhecer que o sucesso de uma empresa está direcionado a habilidade da alta administração em identificar as principais necessidades de estratégias que permitam a satisfação de seus objetivos.

Swaim (2011) relata que na visão do teórico Drucker o objetivo da estratégia é permitir à organização alcançar os resultados que deseja em um ambiente imprevisível e permitir que a organização seja propositalmente oportunista. O autor citado acrescenta que Drucker também afirma que "existem cinco certezas ou pressupostos que fundamentam a estratégia" como pode ser visto no Quadro 03.

Quadro 03: Cinco certezas ou pressupostos que fundamentam a estratégia.

\begin{tabular}{|l|}
\hline $\begin{array}{l}\text { A redução da taxa de natalidade nos países desenvolvidos e o envelhecimento da } \\
\text { população. }\end{array}$ \\
\hline Mudanças na distribuição de renda disponível \\
\hline Definição de desempenho \\
\hline Competitividade global \\
\hline A crescente incongruência entre a globalização econômica e a fragmentação política \\
\hline
\end{tabular}

Fonte: Adaptado Swaim (2011) 
Observa-se de acordo com o quadro 4, que a formulação de uma estratégia bem definida é necessário conhecer o seu publico e sua renda salarial, para que a partir disso estabelecer metas de alcance de desempenho para que se tenha uma competitividade diante da crescente concorrência por meio da globalização e fragmentação politica (SWAIM 2011).

Corroborando com os demais autores anteriormente citados neste estudo, Gamble (2012) afirma que a estratégia de uma empresa consiste nas iniciativas e abordagens desenvolvidas pela administração para atrair clientes e agradá-los, conduzir as operações, promover o crescimento dos negócios e atingir os objetivos de desempenho.

\section{Marketing Estatégico}

A popularidade do marketing cresce a cada dia, principalmente em um cenário de economias que passam por intensas transformações, como o mercado brasileiro, no qual existe um aumento de consumo tanto das tradicionais classes média e alta quanto da classe C; cada vez mais surgem empresas brigando pelo bolso dos consumidores. E é nesse cenário que o marketing surge como visibilidade, tanto das estratégias promocionais por parte das empresas como de sua imagem corporativa em razão de os consumidores estarem a cada dia mais conectados digitalmente (ROCHA, 2015).

Para o autor Peter (2013) o marketing significa que uma organização deve procurar obter lucros ao atender às necessidades de grupos de consumidores. o conceito é muito direto, e tem uma grande carga de validade no senso comum. Talvez por isso seja quase sempre mal entendido, esquecido ou menosprezado.

Na visão de Pereira (2014) o marketing é fundamental para o desenvolvimento das organizações, pois é através dele que se deve gerenciar as comunicações internas, desenvolver melhores estratégias e ações na gestão de satisfação ao cliente, além de cuidar da imagem da empresa, manter o marketing exige atenção e visão de negócios, objetivos, metas e um bom planejamento para que as organizações possam se manter a longo prazo.

E com o avanço das novas tecnologias é necessário que as organizações estejam atentas aos meios de relacionamentos com o cliente e que se adaptem aos novos métodos e modelos de 
negócios, uma forma eficaz de trabalhar a competitividade de uma organização é implantar as ferramentas de marketing (KLOTER, 2005).

Para Rocha (2015) uma vez entendido o conceito de marketing e sua importância para a sobrevivência, é preciso destacar que algumas empresas estão sempre em evidência, seja no mercado, seja nas conversas entre consumidores. Isso, aparentemente, deve-se ao fato de que a necessidade de entender as modificações presentes no mercado, de mapear estrategicamente os consumidores e de adequar-se às demandas de um mercado cada vez mais exigente.

Uma vez conhecendo o consumidor e adequando-se as constantes mudanças impostas pelas tendências do mercado, utiliza-se ferramentas para garantir a atenção dos clientes por meios de estímulos relacionados a suas necessidades (ZENARO, 2013).

Na visão de Doz (2010) fala que devido as rápidas mudanças de mercado e tendências, cria situações complexas em que receitas usuais para sustentação de vantagens não se aplicam, tornando assim a competitividade constantemente desafiada por novos modelos de negócios e o confronto com concorrentes das mais variadas origens, trazendo com elas agregação de valor, reconquistando por meio da inovação.

$\mathrm{O}$ autor ressalta ainda que normalmente a estratégia normalmente baseia-se em uma previsão superior, antecipando-se a mudanças e tendências tornando pioneiro mediante a seus concorrentes, clientes, fornecedores e parceiros. Validando até mesmo ao meio das dificuldades com a necessidade de um forte insight estratégico (DOZ 2010).

Pode citar que o marketing digital é uma forte estratégia dentro das organizações, e contudo, é importante dizer sobre o que é e como se comporta o dito marketing "tradicional". De acordo com Kotlere Keller (2010, p. 4), “O marketing envolve a identificação e a satisfação das necessidades humanas e sociais. Para defini-lo de uma maneira bem simples, pode-se dizer que ele „supre as necessidades lucrativamente”.

Conforme Turchi (2018), algumas inovações são marcantes, atraindo as atenções para o marketing na web, expondo as ações para as mídias sociais como forma de atrair clientes. Tendo em vista que algumas empresas utilizam de outros métodos para veiculação de seus produtos e captação de vendas. 


\section{Marketing Digital}

Para o autor Segura (2009) o marketing digital surgiu como um meio de ações para viabilizar de forma mais segmentada os métodos de comunicação realizada pelas empresas, onde se consegue, através da internet, novos caminhos para a divulgação de produtos e serviços, abrindo oportunidades para a conquista de mais clientes, bem como aumentar sua rede de relacionamentos.

Na visão de Caro (2010) o marketing digital se torna importante para as percepções dos processos decisórios do consumidor, pois é dele que será gerado todas as sensações, desejos e até o reconhecimento do problema que impulsionará o indivíduo a realizar a compra ou não, incluindo também o seu comportamento de pós-compra, onde esta etapa se torna relevante e poderá tornar o consumidor fiel à marca. A realização de um marketing digital eficiente é fundamental para delimitar e impulsionar seguidores e consumidores.

Vaz (2011) fala que a internet captou e ainda capta a cada busca no Google o intimo da sociedade global, no meio natural em que o homem expresse fazendo que o foco desloque do macro para o micro, no modo em que a era digital volte para a valorização do ser, ou seja, pensar small implica iniciar a comunicação de fato com o consumidor.

De acordo com Turchi (2018) uma estratégia bastante utilizada é mensagem interessante, engraçada ou instigante de modo que as pessoas retransmitem a ideia para seu grupo de relacionamento de forma espontânea e gratuita. Oliveira (2000) enfatiza que é necessário bastante concentração de esforços para adaptar-se no desenvolvimento de estratégias para o ambiente da web, de modo que, sejam descobertas necessidades e desejos dos seus consumidores, para que então seja ofertado aos consumidores, serviços e produtos de real valor.

Por fim, Daniel (2015), propõe melhoria na comunicação e o contato com o consumidor, pois exige rapidez e constantes mudanças de preferencias e tendências, tornando a utilização de um planejamento constante para o ambiente digital e físico. 


\section{Vendas}

A globalização teve como resultado uma intensa competição entre as organizações, isso decorre da mudança do comportamento do consumidor. Observa que os clientes estão cada vez mais exigentes, a tecnologia avança rapidamente. O maior desafio está no fato de os gerentes de vendas terem de se adaptar às inúmeras mudanças drásticas desse cenário voltado ao mundo digital (SPIRO, 2010).

Entre essas mudanças Spiro (2010) menciona o avanço da tecnologia que vem causando um grande impacto na gestão de vendas. Atualmente existem inúmeros modelos de negócios virtuais, entre eles as lojas, que podem gerar pedidos de maneira muito eficiente, e mantê-las é muito mais barato que manter uma força de vendas.

Mas apesar dos pontos positivos que a tecnologia tem apresentado o autor Spiro (2010) chama atenção que um site não tem a capacidade de convencer um cliente, de resolver problemas e construir um relacionamento quanto a de um profissional de vendas. Para o autor Futrell (2014), a definição de vendas envolve a comunicação entre o profissional de vendas e o comprador. Ambos discutem as necessidades e falam sobre o produto em questão para ver como ele vai satisfazer as necessidades daquela pessoa. Historicamente o termo vendas teve início nos anos 1940, junto as mudanças de atitude e as necessidades dos militares após a Segunda Guerra Mundial. Com o passar do tempo, as empresas começaram a observar que a técnica utilizada para vender não era eficiente, precisavam focar não apenas no produto, mas no treinamento dos seus vendedores. Por fim, a empresas também observaram que além de treinar os funcionários para venda, deveriam estudar o mercado.

A Partir de então, surgiram às estratégias de marketing dentro das empresas como fator competitivo. Entretanto é importante destacar que o gestor de vendas deve entender qual a relação entre a estratégia de marketing com a área de vendas, já que ela é responsável pela implementação de decisões fundamentais em termos de segmentação, diferenciação e posicionamento da empresa e de produtos (FUTRELL, 2014). É importante ressaltar que há diferentes estratégias a serem aplicadas a cada negócio. Isso implica refletir sobre alguns pontos cruciais para as estratégias de marketing e comunicação.

Na visão de Turchi (2018, p. 210), os maiores desafios da atualidade é a necessidade de maior assertividade na definição do público que se deseja atingir. Deste modo, é imprescindível 
utilizar formas que vão além do costumeiro na analise de perfil sociodemográfico. É fundamental segmentar o perfil por hábitos, comportamentos e atitudes.

Projetar e revisar o publico alvo de maneira adequada é crucial por parte do planejamento estratégico dos executivos de vendas, sendo feito corretamente, consegue assegurar de forma efetiva e eficiente o apoio a clientes. (SPIRO, 2010).

Weinberg (2000) afirma que ainda que sob a ótica do marketing, o impacto de se possuir uma página na internet não garante o sucesso nas vendas por fatores como demora no carregamento da página, falta de organização e informações confusas, ocasiona o insucesso no desejo da compra e pode negativar o posicionamento da marca perante os consumidores.

Na visão de Turchi (2018, p. 233) atuar em um cenário de transformação constante traz grande desafios para todos envolvidos nos processos de vendas e um dos pontos que chama atenção nas empresas é a criação de conteúdos de forma continua, com atualizações continuas tem favorecido o engajamento de clientes com a empresa.

\section{Método}

Conhecer, caracterizar, analisar e elaborar questionamentos sobre um objeto de pesquisa se dispõe atualmente de diversos instrumentos metodológicos. Um dos métodos usado para o estudo é a analise documental enfatizado por Cellard (2008).

Esta pesquisa se utilizará de documentos contendo dados como volume de mercadoria vendida durante o período de três anos antes da implantação das mídias digitais e três anos depois da implantação no grupo empresarial da Região do Cariri, permitindo a aproximação ao objeto estudado para construção do estudo investigativo. Com isso serão adotados procedimentos metodológicos necessários para obter respostas ao questionamento e aos objetivos propostos inicialmente. Para Piana (2009) “A pesquisa permite levantamentos referente aos temas estudados, permitindo a pesquisa bibliográfica para nortear a investigação da pesquisa".

A utilização de documentos em pesquisa deve ser apreciado e valorizado, pois conta com uma vasta riqueza de informação que pode - se extrair e resgatar o seu uso em Ciências 
Humanas e Sociais possibilitando o conhecimento de objetos cujo entendimento precisa de contexto histórico e sociocultural. Como exemplo, a reconstrução de uma historia vivida.

[...] o documento escrito constitui uma fonte extremamente preciosa para todo pesquisador nas ciências sociais. Ele é, evidentemente, insubstituível em qualquer reconstituição referente a um passado relativamente distante, pois não é raro que ele represente a quase totalidade dos vestígios da atividade humana em determinadas épocas. Além disso, muito frequentemente, ele permanece como o único testemunho de atividades particulares ocorridas num passado recente (CELLARD, 2008: 295).

Um dos procedimentos destes estudos é o uso da estatística inferencial e descritiva que permite tomar decisões a partir de elementos amostrais e descreve. A amostragem é referente ao banco de dados do Grupo Empresarial. Segundo Samohyl (2009) "A amostragem é necessária quando a inspeção necessita da destruição do item amostrado". Tendo como estatística descritiva que é a etapa inicial da análise utilizada para descrever e resumir os dados. A disponibilidade de uma grande quantidade de dados e de métodos computacionais muito eficientes revigorou está área da estatística.

Para análise destes dados foi utilizado o teste de normalidade Kolmogorov-Smirnov (BUSSAB, 2006). Os dados comparam o desempenho do grupo empresarial antes e depois da implantação das mídias sociais em 7 (sete) lojas físicas situada nas cidades de Juazeiro do Norte, Crato, Barbalha, Brejo Santo e Iguatu. Tornando assim de natureza quantitativa, utilizando assim uma classificação de produtos em grupos com marcas renomadas. Tornando assim a pesquisa em estudo será quantitativa, pois Rodrigues (2007) afirma que a pesquisa quantitativa traduz em números as opiniões e informações classificadas e analisadas com técnicas estatísticas. Posteriormente os dados serão tratados e tabulados de acordo com seus métodos adotados e informados no procedimento metodológico. A análise será composta pela observação do pesquisador juntamente da fundamentação teórica apresentada no referido estudo.

\section{Análise de Dados}

O presente artigo tem como objetivo geral avaliar a influência do marketing digital sob o volume de vendas em um grupo empresarial da Região do Cariri - CE. 
Para testar se o volume de acessos as redes sociais afetam as vendas nas diversas filiais de na referida rede de lojas, foram colhidos os volumes de vendas mensais nos 43 meses antes da implantação das redes sociais, ou seja, de janeiro de 2003 a julho de 2016. Também foram colhidos os volumes de vendas nos 25 meses seguintes, após o lançamento da venda digital e criação de redes sociais. O teste de normalidade utilizado neste trabalho foi o teste de Kolmogorov-Smirnov (BUSSAB, 2006).

Para uma melhor compreensão os dados encontram-se no quadro 06. A série com os totais de vendas mês a mês para a loja 1, estão ilustradas no Gráfico 01.

Gráfico 01: Volume totais de vendas mensais entre janeiro de 2003 e agosto de 2018 na loja 01 da rede.

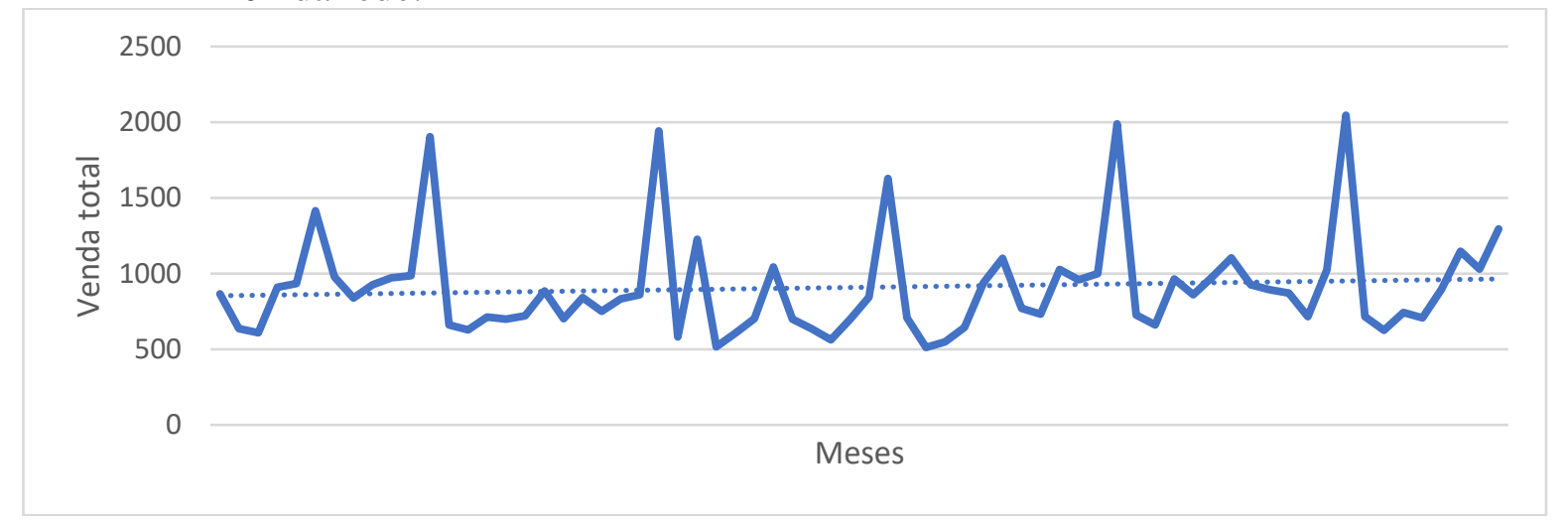

Fonte: Dados da pesquisa 2018.

A linha pontilhada representa a tendência de comportamento das vendas, neste caso, indica a existência de um leve crescimento. Para confirmar se, de fato, existe o referido crescimento, faz-se necessário a execução de um teste de igualdade de médias.

Testar uma hipótese consiste em tomar uma decisão com base critérios preestabelecidos e em dados colhidos de amostras. Ao realizar um teste de hipótese é possível cometer dois tipos de erros: O Erro tipo I, ocorre quando se rejeita uma hipótese nula quando verdadeira e o Erro tipo II, consiste em não rejeitar a hipótese nula quando falsa. Costumeiramente preocupa-se mais em controlar o erro tipo 1, definindo-se a hipótese nula de tal modo que cometer um erro do tipo 1 seja o menos desejado. Por exemplo, em princípios de direito, como hipótese nula toma-se sempre a inocência do réu, uma vez que rejeitar essa hipótese implica em condenar um inocente. Um erro bem menos tolerável que absorver um culpado. O erro tipo 1 é controlado 
admitindo-se para ele uma pequena probabilidade. Essa probabilidade é dita nível descritivo e é denotada por $\alpha$, é costumeiro tomar-se $\alpha=5 \%$.

Para cada uma das lojas da rede foi calculado o volume médio de vendas antes da implantação das redes sociais, cujo valor será indicado por: $\bar{x}_{\text {Antes. }}$ E, analogamente, o volume médio das vendas depois da implantação das redes sociais: $\bar{x}_{\text {Depois. }}$ Observe que: $\bar{x}_{\text {Antes }}$ e $\bar{x}_{\text {Depois }}$ são médias amostrais. Se $\mu_{\text {Antes}}$, representa a média mensal populacional de vendas antes da

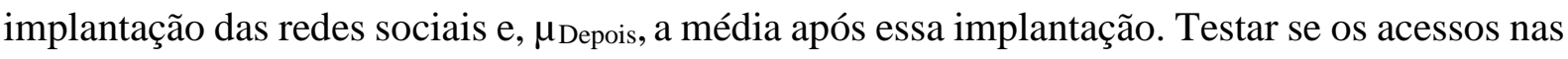
redes, por parte dos clientes, promoveram alguma alteração significativa na média de vendas. Isto equivale a testar se: $\mu_{\text {Antes }} \neq \mu_{\text {Depois, }}$ ou seja, se houve alguma alteração, para menos ou

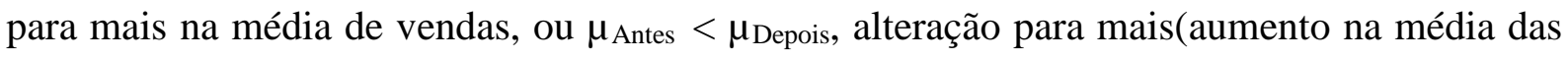

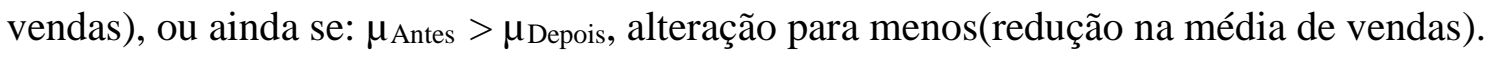

Foi utilizado o teste $t$ de Student para igualdade entre duas médias, especificando se ocorreu um aumento ou redução nas médias. Ou seja, foram testadas as hipóteses:

Hipótese nula: $\mu_{\text {Antes }}=\mu_{\text {Depois }}$ contra a hipótese alternativa $\mu_{\text {Antes }}<\mu_{\text {Depois. }}$. Este tipo de teste foi executado quando a média amostral antes $\bar{x}_{\text {Antes }}$ apresentou-se inferior à média amostral depois, $\bar{x}_{\text {Depois. }}$ Esse tipo de teste é dito teste unilateral a direita.

$$
\begin{aligned}
& \mathrm{H}_{0}: \mu_{\text {Antes }}=\mu_{\text {Depois }} \text { contra } \\
& \mathrm{H}_{\text {Alternativa }}: \mu_{\text {Antes }}<\mu_{\text {Depois }}
\end{aligned}
$$

\begin{tabular}{|c|c|c|c|c|}
\hline & \multicolumn{3}{|c|}{ VENDA LOJA 1} \\
\hline & & Presencial & Digital & Total \\
\hline \multirow{3}{*}{ 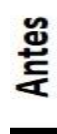 } & $\mathbf{n}$ & 43 & & 43 \\
\hline & Média & 864,53 & & 864,53 \\
\hline & DP & 328,34 & & 328,34 \\
\hline \multirow{3}{*}{ 능 } & $\mathbf{n}$ & 25 & 25 & 25 \\
\hline & Média & 866,04 & 119,20 & 985,24 \\
\hline & DP & 344,24 & 62,16 & 344,58 \\
\hline \multicolumn{2}{|c|}{ Hipótese Alternativa } & $\mu A<\mu D$ & & $\mu A<\mu D$ \\
\hline \multicolumn{2}{|c|}{ TN Antes } & 0,081 & & 0,081 \\
\hline \multicolumn{2}{|c|}{ TN Depois } & 0,081 & & 0,072 \\
\hline \multicolumn{2}{|c|}{ Sa2/Sd2 } & 0,91 & & 0,91 \\
\hline \multicolumn{2}{|r|}{ Sp } & 334,21 & & 334,34 \\
\hline \multicolumn{2}{|c|}{ T_o } & $-0,02$ & & $-1,44$ \\
\hline \multicolumn{2}{|c|}{ p-valor } & 0,493 & & 0,078 \\
\hline
\end{tabular}

Tabela 02: Estatísticas para o teste t-Student de diferenças de médias

Fonte: Dados da pesquisa 2018. 
Onde:

n, Média e DP são respectivamente, tamanho da amostra, média amostral e desvio padrão amostral, para os dados antes e depois da implantação das redes sociais;

TN Antes: É o p-valor para o teste de normalidade para as vendas antes da implantação das redes sociais;

TN Depois: É p-valor para o teste de normalidade para as vendas depois da implantação das redes sociais;

Sa2/Sd2: É o quociente entre as variâncias amostrais, antes e depois da implantação das redes sociais

Sp: É o desvio padrão ponderado, usado sempre que for aceita a hipótese de igualdade de variâncias;

T_0: É o valor da estatística de teste: $\frac{\bar{x}_{A}-\bar{x}_{D}}{s_{p} \sqrt{\frac{1}{n_{A}}+\frac{1}{n_{D}}}}$;

p-valor: É a probabilidade de ocorrer uma estatística mais negativa a hipótese nula do que T_0.

É padrão rejeitar a hipótese nula sempre que p-valor seja menor que $0,05=5 \%$. Isto quer dizer que diante da ocorrência de algo tão raro, é mais prudente admitir que a hipótese nula é que está errada e passar a admitir uma hipótese alternativa, costumeiramente predefinida. Em alguns casos, se aceita a hipótese nula até o limite de p-valor $=0,01$, rejeitando-a apenas quando p-valor for inferior a esse número. Para testar a hipótese de igualdade de médias, o primeiro passo é testar se as distribuições das variáveis podem ser consideradas normais BUSSAB (2006).

Para o caso da Loja 1, observa-se na tabela 1 que TN Antes e TN Depois são ambos superiores a 0,05 , implicando na não rejeição da hipótese de normalidade das vendas tanto antes da implantação das redes sociais quanto depois. Seja considerando apenas as vendas presenciais, ou as vendas totais, que é a soma das vendas presenciais com as vendas digitais, conforme mostra a tabela 1 na coluna Venda Total. 
O próximo teste requerido é o teste para igualdade de variâncias. A estatística utilizada será: $\frac{s_{A}^{2}}{S_{D}^{2}}$, que tem distribuição $\mathrm{F}\left(n_{A}-1, n_{B}-1\right)$ para as amostras em questão $\mathrm{F}(42,24)$. A hipótese de igualdade entre as variâncias só é rejeitada se $\frac{S_{A}^{2}}{S_{D}^{2}}<0,48$ ou $\frac{S_{A}^{2}}{S_{D}^{2}}>2,21$ ao nível de $5 \%$. Para os dados da Loja $1, \frac{S_{A}^{2}}{S_{D}^{2}}=0,91$, conforme tabela 1, tanto para as vendas presenciais quanto para as vendas totais, ou seja, vendas presencias mais as digitais, ou seja, em qualquer um dos casos, conclui-se que as variâncias são as mesmas para os dados antes e depois.

Agora basta finalizar o teste de igualdade de médias usando-se a estatística T_0 ou o seu p-valor associado.

Para a Loja 1 e ao nível de 5\% conclui-se que não houve alteração entre as médias pois $\mathrm{p}$-valor $=0,493=49,3 \%$ para as vendas presenciais e $\mathrm{p}$-valor $=0,078=7,8 \%$ para as vendas digitais.

Ambas superiores ao limite mínimo para o p-valor $=0,05=5 \%$. Logo, não se rejeita a hipótese de igualdade entre as médias, isto que dizer que a média de vendas é a mesma antes e depois da inclusão das redes sociais. Outra investigação de interesse pode ser se um número mais elevado de acessos nas redes sociais por parte dos clientes proporciona aumento nas vendas. Uma primeira impressão pode ser tirada examinando o diagrama de dispersão entre o número de acessos e o volume de vendas dado no gráfico 02 a seguir:

Gráfico 02: Diagrama de dispersão entre os acessos nas redes sociais e as vendas na Loja 1.

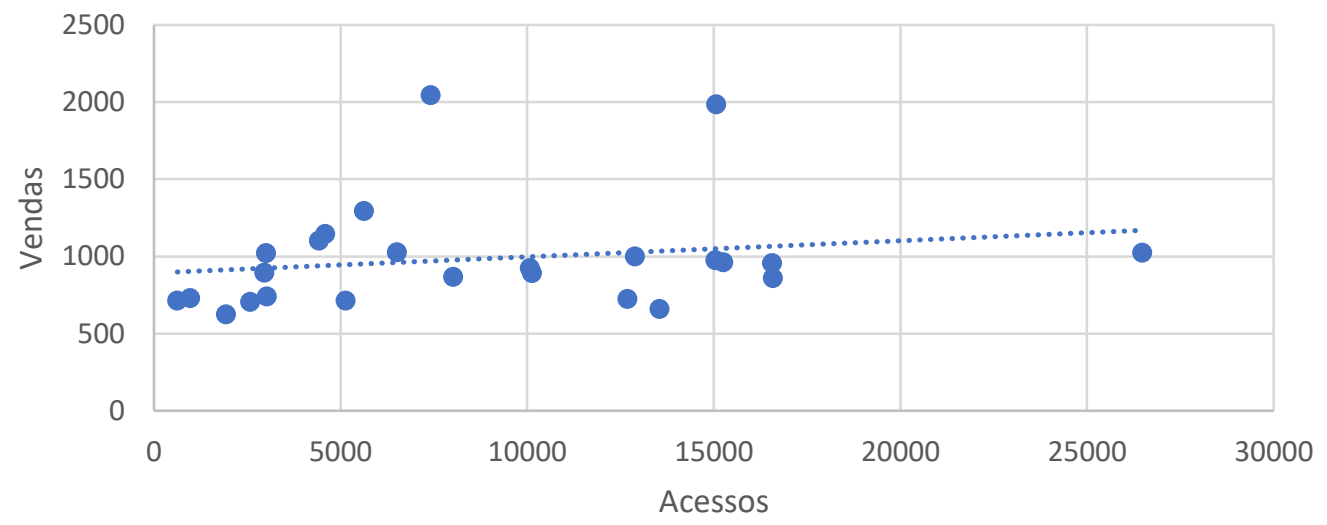

Fonte: Dados da pesquisa 2018. 
Observa-se uma leve tendência de aumento, ilustrada pela linha pontilhada. Isto quer dizer quanto maior o número de acessos, maior o número de vendas na Loja 1 . A fragilidade desse resultado é decorrente do baixo valor do coeficiente de correlação de Pearson entre as variáveis, acessos e vendas.

O coeficiente de correlação de Pearson é definido por: $\operatorname{Corr}(\mathrm{X}, \mathrm{Y})=\frac{\sum_{i=1}^{n} x_{i} y_{i-n} \bar{x} \bar{y}}{\sqrt{\left(\sum x_{i}^{2}-n \bar{x}^{2}\right)\left(\sum y_{i}^{2}-n \bar{y}^{2}\right)}}$. Se Corr $(\mathrm{X}, \mathrm{Y})$ estiver perto de -1 , indicará uma correlação inversa entre as variáveis, ou seja, se uma cresce a outra decresce. Se $\operatorname{Corr}(\mathrm{X}, \mathrm{Y})$ estiver próximo de 1, indicará uma correlação direta, crescendo uma a outra também cresce. Se próximo de zero, indica inexistência de correlação. A correlação entre os acessos e as vendas na Loja 1 é de: Corr(Acessos, Vendas Loja 1) = 0,191. Indicando uma baixa correlação entre as variáveis, ou seja, os acessos as redes sociais afetam muito pouco as vendas na Loja 1.

Resumindo, pode-se afirmar que não houve aumento nas vendas na Loja 1 com o advento das redes sociais mesmo considerando o total de vendas, ou seja, as vendas presenciais mais as vendas digitais. Analogamente pode-se concluir sobre as outras lojas da rede. No quadro 06 apresenta, por linha o gráfico do volume de vendas mês a mês, a dispersão entre os acessos as redes sociais da rede e o volume de venda da loja e as estatísticas para o teste de igualdade de médias conforme realizado para a loja 1.

O quadro 04 demonstra o resumo de seis lojas investigadas, é importante destacar que no total foram trabalhadas sete lojas, a loja 01 consta no gráfico 01 anteriormente apresentado. 
Quadro 04: Resumo das seis lojas pesquisadas.

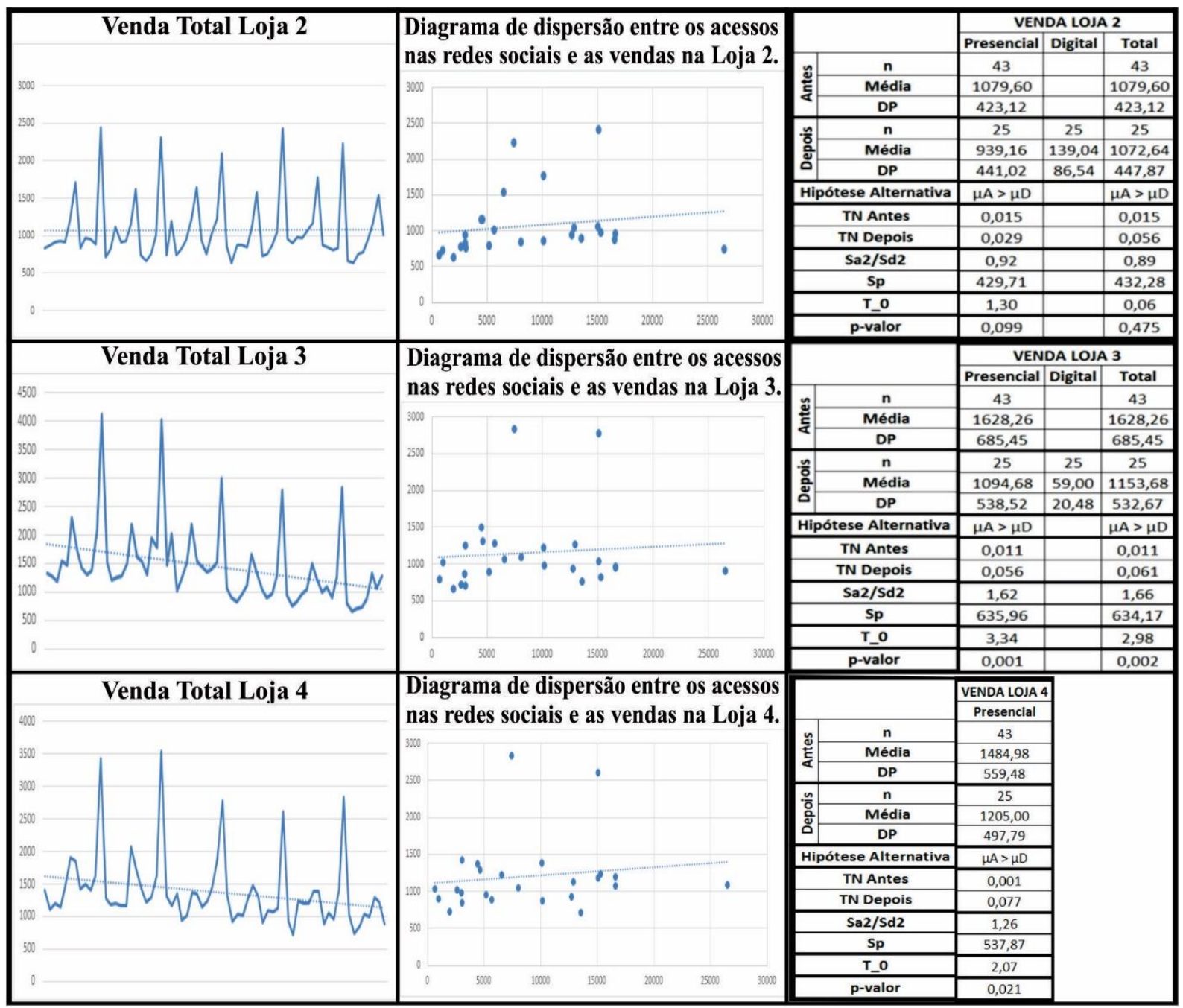

Fonte: Dados da pesquisa 2018. 
Quadro 05: Resumo das seis lojas pesquisadas.

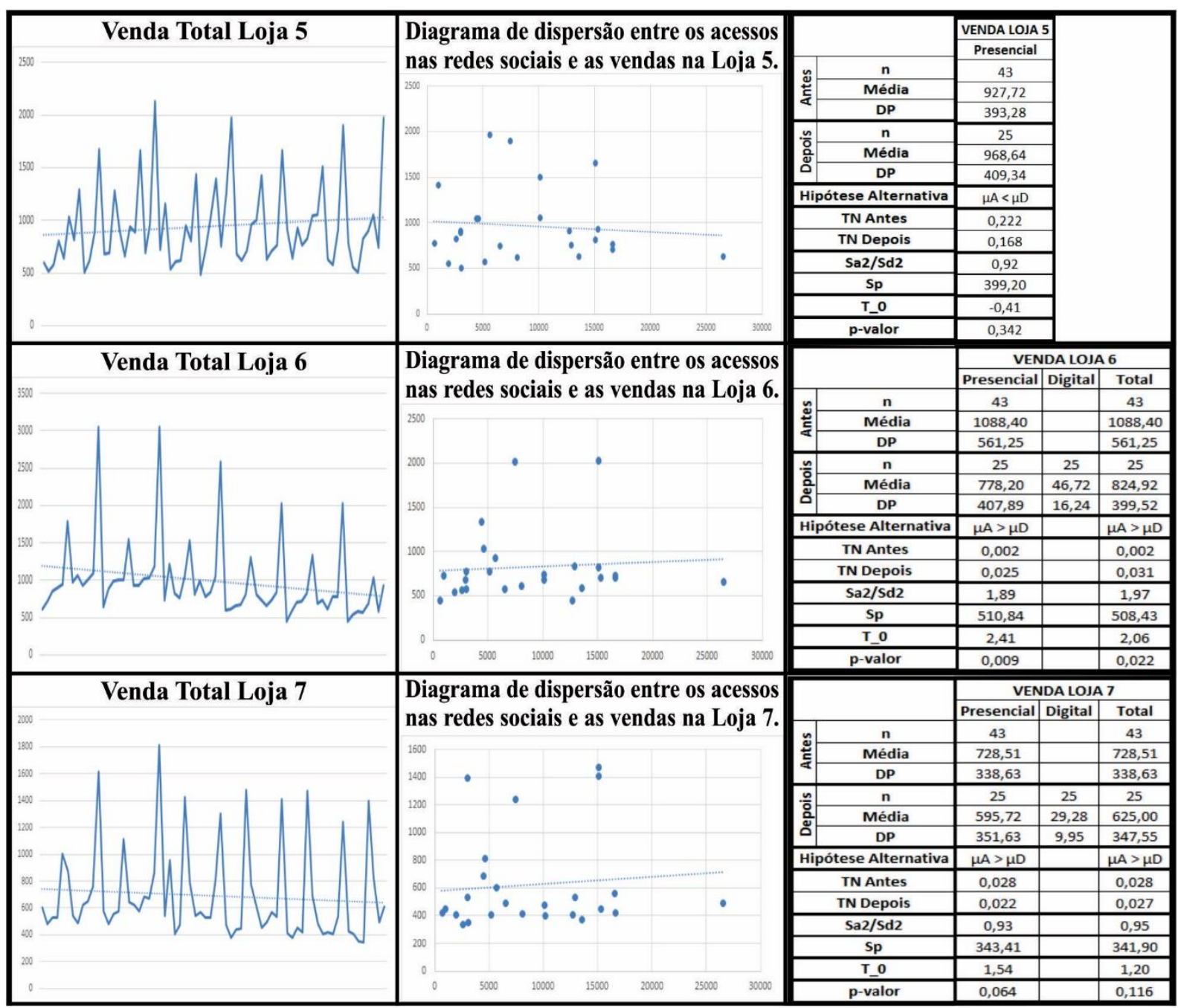

Fonte: Dados da pesquisa 2018.

\section{Considerações Finais}

O que se observou (Quadro 06) foi: Que em apenas duas lojas (Loja 1 e Loja 5), as médias amostrais antes da implantação da rede social foram inferiores a médias depois dando uma impressão de aumento nas vendas, impressões essas que foram descartadas com os testes de médias t-Studant ao nível de 5\%. Em todas as outras lojas investigadas, as médias amostrais 
depois da implantação da rede social foram inferiores, dando impressão de redução nas vendas, impressões que foram confirmadas pelos testes para diferença de média t-Student, a nível de $5 \%$, apenas para as lojas 3 e 6.

Quadro 06: Considerações Finais

\begin{tabular}{|c|c|c|c|c|c|c|c|}
\hline \multirow{4}{*}{ Lojas } & \multirow{2}{*}{\multicolumn{5}{|c|}{$\begin{array}{c}\text { CONSIDERAÇÕES FINAIS } \\
\text { Testes }\end{array}$}} & \multirow{2}{*}{\multicolumn{2}{|c|}{ Testes }} \\
\hline & & & & & & & \\
\hline & \multicolumn{2}{|c|}{ Normalidade } & \multicolumn{3}{|c|}{ Igualdade } & \multirow{2}{*}{$\begin{array}{c}\text { Correlação } \\
\text { entre os } \\
\text { acessos e } \\
\text { as vendas }\end{array}$} & \multirow[b]{2}{*}{ Conclusão } \\
\hline & Antes & Depois & Variâncias & $\begin{array}{l}\text { Médias } \\
\text { Vendas }\end{array}$ & $\begin{array}{c}\text { Médias } \\
\text { Vendas } \\
\text { Total }\end{array}$ & & \\
\hline Loja 2 & $\begin{array}{c}\text { Aceita à } \\
1 \%\end{array}$ & $\begin{array}{c}\text { Aceita à } \\
1 \%\end{array}$ & $\begin{array}{c}\text { Aceita a } \\
5 \%\end{array}$ & $\begin{array}{c}\text { Aceita a } \\
5 \%\end{array}$ & $\begin{array}{c}\text { Aceita a } \\
5 \%\end{array}$ & 0,165 & $\begin{array}{l}\text { Não houve redução } \\
\text { significativa na média de } \\
\text { vendas. Os acessos a rede } \\
\text { social da rede de lojas, afeta } \\
\text { um pouco e positivamente } \\
\text { as vendas totais da loja } 2 \text {. }\end{array}$ \\
\hline Loja 3 & $\begin{array}{c}\text { Aceito à } \\
1 \%\end{array}$ & $\begin{array}{c}\text { Aceito à } \\
1 \%\end{array}$ & $\begin{array}{c}\text { Aceita a } \\
5 \%\end{array}$ & $\begin{array}{c}\text { Rejeita a } \\
5 \%\end{array}$ & $\begin{array}{c}\text { Rejeita-se } \\
\text { a } 5 \%\end{array}$ & 0,090 & $\begin{array}{l}\text { Houve redução na média de } \\
\text { vendas e os acessos a rede } \\
\text { social da rede lojas afetam } \\
\text { muito pouco, também } \\
\text { positivamente as vendas } \\
\text { totais das vendas da Loja } 3\end{array}$ \\
\hline Loja 4 & $\begin{array}{c}\text { Aceito à } \\
0,1 \%\end{array}$ & $\begin{array}{c}\text { Aceito à } \\
1 \%\end{array}$ & $\begin{array}{c}\text { Aceita a } \\
5 \%\end{array}$ & $\begin{array}{c}\text { Rejeita a } \\
5 \%\end{array}$ & $\begin{array}{c}\text { Rejeita-se } \\
\text { a } 5 \%\end{array}$ & 0,139 & $\begin{array}{l}\text { Houve redução na média de } \\
\text { vendas e os acessos a rede } \\
\text { social afeta pouco e } \\
\text { positivamente as vendas } \\
\text { totais da Loja } 4\end{array}$ \\
\hline Loja 5 & $\begin{array}{c}\text { Aceito à } \\
1 \%\end{array}$ & $\begin{array}{c}\text { Aceito à } \\
1 \%\end{array}$ & $\begin{array}{c}\text { Aceita a } \\
5 \%\end{array}$ & $\begin{array}{c}\text { Aceita a } \\
5 \%\end{array}$ & $\begin{array}{c}\text { Aceita a } \\
5 \%\end{array}$ & $-0,094$ & $\begin{array}{l}\text { Não houve acréscimo na } \\
\text { média de vendas e os } \\
\text { acessos a rede social afeta } \\
\text { pouco mas negativamente as } \\
\text { vendas totais das da Loja } 5\end{array}$ \\
\hline Loja 6 & $\begin{array}{c}\text { Aceito à } \\
0,1 \%\end{array}$ & $\begin{array}{c}\text { Aceito à } \\
0,1 \%\end{array}$ & $\begin{array}{c}\text { Aceita a } \\
5 \%\end{array}$ & $\begin{array}{c}\text { Rejeita a } \\
5 \%\end{array}$ & $\begin{array}{c}\text { Rejeita-se } \\
\text { a } 5 \%\end{array}$ & 0,081 & $\begin{array}{l}\text { Houve redução na média de } \\
\text { vendas e os acessos a rede } \\
\text { social da rede lojas afetam } \\
\text { muito pouco } \\
\text { positivamente as vendas } \\
\text { totais das vendas da Loja } 6\end{array}$ \\
\hline Loja 7 & $\begin{array}{c}\text { Aceito à } \\
1 \%\end{array}$ & $\begin{array}{c}\text { Aceito à } \\
1 \%\end{array}$ & $\begin{array}{c}\text { Aceita a } \\
5 \%\end{array}$ & $\begin{array}{c}\text { Rejeita a } \\
5 \%\end{array}$ & $\begin{array}{c}\text { Rejeita-se } \\
\text { a } 5 \%\end{array}$ & 0,093 & $\begin{array}{l}\text { Não houve redução } \\
\text { significativa na média de } \\
\text { vendas. Os acessos a rede } \\
\text { social da rede de lojas } \\
\text { afetam muito pouco e } \\
\text { positivamente as vendas da } \\
\text { loja } 7\end{array}$ \\
\hline
\end{tabular}

Fonte: Dados da pesquisa 2018. 
Ou seja, para todas as outras lojas, não é possível afirmar que houve alteração nas vendas, nem para mais nem para menos. Apenas as lojas 3 e 6, pode-se afirmar ao nível de $5 \%$ que houve redução nas vendas. Quanto a influência dos acessos nas vendas.

De um modo geral observou-se baixa correlação entre os acessos e as vendas por loja. As lojas que apresentaram reações positivas, ou seja, quanto maior o número de acesso, maior as vendas, foram as lojas 1, 2 e 4. As lojas: 3, 6 e 7; apesar de apresentar correlação positiva, mas pouco significativa, pois ficou abaixo dos $10 \%$. Isto quer dizer que os acessos praticamente não afetam as vendas nessas lojas. A loja 5, também com correlação inferior a 10\%, mas negativa, ou seja, quanto maior o número de acesso menor as vendas nesta loja. Provavelmente os clientes dessa loja acessam pouco as redes sociais, quando o faz, optam por comprar noutra filial da rede.

Gráfico 03: Conclusão de todas as lojas.

\begin{tabular}{|c|c|c|c|c|c|}
\hline \multirow{3}{*}{ Todas as lojas } & & & \multicolumn{3}{|c|}{ Todas as Lojas } \\
\hline & & & Presencial & Digital & Total \\
\hline & \multirow{3}{*}{$\frac{\text { }}{\frac{c}{4}}$} & $\mathbf{n}$ & 43 & & 43 \\
\hline 25000 & & Média & 7802,00 & & 7802,00 \\
\hline & & DP & 2772,44 & & 2772,44 \\
\hline 20000 & \multirow{3}{*}{$\frac{n}{\circ}$} & $\mathbf{n}$ & 25 & 25 & 25 \\
\hline & & Média & 6447,44 & 417,76 & 6865,20 \\
\hline & & DP & 2686,38 & 160,91 & 2710,36 \\
\hline 10000 & \multicolumn{2}{|c|}{ Hipótese Alternativa } & $\mu \mathrm{A}>\mu \mathrm{D}$ & & $\mu \mathrm{A}>\mu \mathrm{D}$ \\
\hline & & TN Antes & 0,043 & & 0,043 \\
\hline 5000 & & TN Depois & 0,120 & & 0,126 \\
\hline l & & Sa2/Sd2 & 1,07 & & 1,05 \\
\hline $\begin{array}{lllllllllllllllllll}7 & 8 & 9 & 10 & 11 & 12 & 13 & 14 & 15 & 16 & 17 & 18 & 19 & 20 & 21 & 22 & 23 & 24 & 25\end{array}$ & & Sp & 2741,45 & & 2750,02 \\
\hline _-Acesso - Venda Fisica - Venda Digital - Venda Total & & T_0 & 1,96 & & 1,35 \\
\hline -Acesso - Venda Fisica - Venda Digital - Venda Total & & p-valor & 0,027 & & 0,090 \\
\hline
\end{tabular}

Fonte: Dados da pesquisa 2018.

Visualmente o gráfico acima parece querer dizer que os acessos a rede social da rede de lojas (em azul) não afeta as vendas na loja física (em vermelho) e muito pouco a venda digital (em verde). Os testes realizados, provam que: houve redução significativa na média de venda física da rede de lojas, antes e depois da implantação da rede social ( $\mathrm{p}$-valor $=0,027<0,05=$ $5 \%)$.

Mas, ao juntar as vendas físicas com as digitais, a conclusão é que a redução nas vendas não é significativa, ao nível de $5 \%$, pois $\mathrm{p}$-valor $=0,09>0,05=5 \%$. Isto pode querer dizer que 
alguns clientes podem ter migrado para compra digital, usufruindo da comodidade de comprar em sua casa.

Quanto a influências nas vendas pelos acessos. Na venda física os acessos parecem não afetar tanto, em torno de 10\%, (Corr = 0,091 =9,1\%). Bem inferior a correlação entre os acessos e a venda digital (Corr $=0,264=26,4 \%)$. De um modo geral, os acessos afetam as vendas positivamente em torno de $10 \%($ Corr $=0,106=10,6 \%)$.

Conclui-se que os resultados obtidos indicam que em algumas lojas apresentou redução em seu volume de vendas após a utilização da rede social, toda via no conjunto de todas as lojas da rede o índice de vendas após a utilização das mídias houve acrescimento em seu volume presencial e que as vendas digitais contribuíram timidamente para esse crescimento, tendo em vista a eficácia das redes sociais no sentido de promover os produtos e promoções atraindo consumidores para as lojas física.

Os resultados deste estudo evidenciam que é fundamental para as empresas, a aposta estratégica e a utilização de ferramentas para que lhes permitam alavancar os proveitos que podem obter do relacionamento com os clientes nas redes sociais.

\section{Referências}

BUSSAB, Wilton O; MORETTIN, Pedro A. Estatística básica. São Paulo: Atual, 1986.

CELLARD, A. A análise documental. In: POUPART, J. et al. A pesquisa qualitativa: enfoques epistemológicos e metodológicos. Petrópolis, Vozes, 2008.

CARO, Abrão. Comportamento do Consumidor e a Compra Online: uma análise multicultural. Tese (Pós-Graduação) - Universidade de São Paulo, 2010.

DANIEL. Quais são os 8Ps do Marketing Digital. Disponível em: <http://dgmarketingdigital.com.br/quais-sao-os-8ps-do-marketing-digital/>. Acesso em: $03 \mathrm{de}$ setembro de 2018.

DOZ, Yves, KOSONEN, Mikko. Fast: Como usar a agilidade estratégica para vencer. Bookman, jan. 2010.

FUTRELL, Charles M. Vendas: fundamentos e novas práticas de gestão. Saraiva, 2003. 
GAMBLE, John E. Fundamentos da administração estratégica [recurso eletrônico] : a busca pela vantagem competitiva 2. ed. - Dados eletrônicos. - Porto Alegre : AMGH, 2012

GRACIOSO, Francisco. Marketing Estratégico - Planejamento Estratégico Orientado Para o Mercado - Atlas, $6^{\text {a }}$ Ed. 2007

KOTLER, P. Administração em marketing: a edição do novo milênio.

SP: Prentice Hall, 2005.

OLIVEIRA, Maxwell Ferreira de. Metodologia científica: um manual para a realização de pesquisas em Administração. Catalão, 2011.

OLIVEIRA, Djalma de Pinho Rebouças de. Planejamento estratégico: conceitos, metodologia e práticas 34. ed. - São Paulo : Atlas, 2018.

OLIVEIRA, Carla Cintia de. Marketing Digital: Um estudo exploratório sobre a utilização das mídias digitais como canal de comunicação. Maringá: Faculdade Alvorada, 2010.

PETER, J. Paul. Introdução ao marketing: criando valor para o cliente. $1^{\circ}$ ed. SP: Saraiva,2013.

PEREIRA, 1. .Estratégias de marketing digital utilizadas para o posicionamento de marca e aumento de vendas de uma empresa em Brasília. Faculdade de Tecnologia e Ciências Sociais Aplicadas FATECS. Brasília, 2014.

PIANA, MC. A construção do perfil do assistente social no cenário educacional [online]. São Paulo: Editora UNESP; São Paulo: Cultura Acadêmica, 2009. 233 p. ISBN 978-85-7983038-9. Available from SciELO Books < http://books.scielo.org >

RODRIGUES, William Costa, Metodologia Cientifica. Paracambi. FAETEC/IST, 2007.

ROCHA, Marcos. Marketing estratégico - São Paulo: Saraiva, 2015.

SAMOHYL, Robert Wayne, 1947 - Controle estatísticos da qualidade / Rio de Janeiro: Elsevier 2009.

SWAIM, Robert W. A estratégia segundo Drucker : estratégias de crescimento e insights de marketing extraídos da obra de Peter Drucker - Rio de Janeiro : LTC, 2011.

SEGURA, M. C. O estudo do Marketing Digital versus Marketing Tradicional e a percepção das suas campanhas por parte dos consumidores no mercado virtual a tradicional.2009. f. 51. Dissertação (Mestrado em estatística e Gestão da Informação) Instituto Superior de Estatística e Gestão de Informação da Universidade Nova de Lisboa, Lisboa,2009. 
SPIRO, Rosann L. Gestão da força de vendas. 12. ed. - Dados eletrônicos. - Porto Alegre : AMGH, 2010.

SPIRO, Rosann L., RICH, A., STANTON, William J. Gestão da Força de Vendas. ArtMed, 09/2010.

TURCHI, Sandra R. Estratégia de Marketing Digital e E-Commerce, $2^{a}$ edição. Atlas, $02 / 2018$

VAZ, Conrado Adolpho. Os 8 Ps do Marketing Digital : O seu guia estratégico de marketing digital / Novatec Editora, São Paulo, 2011.

WEINBERG, Bruce D.; Don't Keep Your Internet Customers Waiting too Long at the Virtual Front Door; Journal of Interactive Marketing; Vol. 14, Nr. 1; Winter 2000; pp. 30-39

ZENARO, Marcelo, Pereira, Maurício Fernandes . Marketing estratégico para organizações e empreendedores: guia prático e ações passo a passo. Atlas, 08/2013.

Como citar este artigo (Formato ABNT):

SILVA, Francisco Wagner Alves da; LIMA, Pedro Ferreira de; LIMA, Márcia Maria Leite. Marketing Digital como Estratégia Competitiva dentro das Organizações: Um Estudo de Caso em uma Rede Empresarial na Região do Cariri - CE. Id on Line Rev.Mult. Psic., 2018, vol.12, n.42, Supl. 1, p. 85-108. ISSN: 1981-1179.

Recebido: 29/10/2018;

Aceito: $03 / 11 / 2018$ 